Research Article

\title{
Octaband WWAN/LTE Dual-Antenna System Decoupled by Two Neutralization Lines with Inductors for Smart Phones
}

\author{
Yan Wang $\mathbb{D D}^{1}$ and Zhengwei Du $\mathbb{D D}^{2}$ \\ ${ }^{1}$ Key Laboratory for Information Science of Electromagnetic Waves, School of Information Science and Technology, \\ Fudan University, Shanghai 200433, China \\ ${ }^{2}$ State Key Laboratory on Microwave and Digital Communications, \\ Tsinghua National Laboratory for Information Science and Technology, Department of Electronic Engineering, \\ Tsinghua University, Beijing 100084, China
}

Correspondence should be addressed to Yan Wang; yanwang_fd@fudan.edu.cn

Received 18 July 2021; Revised 6 November 2021; Accepted 25 November 2021; Published 6 December 2021

Academic Editor: Stefano Selleri

Copyright (C) 2021 Yan Wang and Zhengwei Du. This is an open access article distributed under the Creative Commons Attribution License, which permits unrestricted use, distribution, and reproduction in any medium, provided the original work is properly cited.

\begin{abstract}
A decoupled octaband WWAN/LTE dual-antenna system occupying a size of $80 \mathrm{~mm} \times 15 \mathrm{~mm} \times 6.8 \mathrm{~mm}$ for smart phones is proposed. The proposed antenna system consists of two antenna elements with symmetrical geometry, two neutralization lines (NLs) with embedded inductor, and an inverted-T branch. The two NLs mainly reduce the mutual coupling at the desired lower $(704-960 \mathrm{MHz})$ frequency band, while the inverted-T branch mainly reduces the mutual coupling at the desired higher $(1710-2690 \mathrm{MHz})$ frequency band. The fabricated prototype has a $-6 \mathrm{~dB}$ impedance bandwidth of $0.3 \mathrm{GHz}(0.69-0.99 \mathrm{GHz})$ and $1.2 \mathrm{GHz}(1.66-2.86 \mathrm{GHz})$ which cover the LTE700, GSM850, GSM900, DCS, PCS, UMTS, LTE2300, and LTE2500 bands. Within these bands, the measured mutual couplings are lower than $-10 \mathrm{~dB}$. The measured antenna efficiencies are about $42.6 \%-60 \%$ and $58.3 \%-78.7 \%$ at the desired lower and higher frequency bands, respectively. The diversity performance and the SAR performance are also evaluated.
\end{abstract}

\section{Introduction}

Multi-input and multi-output (MIMO) is one of the critical techniques for the fifth-generation (5G) mobile communication [1]. For a MIMO system, the good performance comes from the multiple antennas with a low correlation [2]. That is, low mutual coupling among the multiple antennas is requested. Nevertheless, because most of the spaces in smart phones are reserved for the display, cameras, battery, and PCB, only small spaces are left to design antenna [3]. Thus, designing multiple antennas with low mutual coupling in the limited space of smart phones is very challenging.

The open literature has proposed some efficient methods to reduce the mutual coupling. For example, orthogonal polarization [4], orthogonal pattern [5], orthogonal phase [6], and orthogonal modes [7] are proposed. In [8], the loop antenna loaded with a lumped capacitor could be applied to isolate the two antenna elements. In [9], a metasurface above the antenna array is studied. Separating discrete antenna element with certain distance can also achieve low mutual coupling $[10,11]$. Also, the concept of common mode and differential mode is studied to reduce the mutual coupling in $[12,13]$. In addition, the decoupling network [14], grounded branch [15], parasitic element [16], and neutralization line [17] could introduce a new coupling to reduce the mutual coupling. Although the above methods are promising for practical applications, most of them usually reduce the mutual coupling at the higher frequency band above $1.7 \mathrm{GHz}$.

For the frequency bands lower than $1 \mathrm{GHz}$, which is very important for the operators to realize the wide area coverage, the antenna size related to the wavelength is very small. Thus, decoupling the dual-antenna working at these bands is more challenge [18]. To address this challenge, the theory of characteristic mode is applied $[18,19]$. In $[20,21]$, the neutralization line was applied to decouple two antennas 
operating at the LTE700 (704-787 MHz)/LTE2500 (2500-2690 MHz) bands [20] and the GSM850 (824-894 MHz)/GSM900 (1710-1880 MHz)/PCS (1920-2170 MHz)/LTE2300 (880-960 MHz)/DCS $(1850-1990 \mathrm{MHz}) / \mathrm{UMTS}$ (2300-2400 MHz)/LTE2500 bands [21]. In [22, 23], to cover all the eight bands (LTE700/ GSM850/GSM900/DCS/PCS/UMTS/LTE2300/LTE2500), the crossed neutralization line [22] and the folded forkshaped grounded branch [23] are proposed. However, the antenna efficiency in $[22,23]$ at the lower band is only $32 \%$ which is a bit low for practical applications.

In this letter, we propose another octaband dual-antenna system covering the LTE700, GSM850, GSM900, DCS, PCS, UMTS, LTE2300, and LTE2500 bands with the antenna efficiency of higher than $42 \%$. To better show the contribution of the proposed design, Table 1 compares the figures of merit of some typical dual-antenna systems. For the mobile antenna, the higher efficiency with wide bandwidth is very important and useful for practical applications. The main contribution is that the proposed dual-antenna system could cover all the WWAN/LTE bands with higher efficiency. This letter is organized as follows. Section 2 describes the antenna geometry. In Section 3, the working mechanism is analyzed. The measured results are illustrated in Section 4. Finally, Section 5 summaries this paper.

\section{Antenna Configuration with Detailed Dimensions}

The geometry of the dual-antenna system with detailed dimensions is given in Figure 1. As seen in Figure 1(a), the dual-antenna system is located at the top part of the printed circuit board (PCB). The substrate of the PCB is a $0.8 \mathrm{~mm}$ thick FR4-epoxy with a length of $155 \mathrm{~mm}$ and a width of $80 \mathrm{~mm}$. Its relative permittivity is 4.4 and its loss tangent is 0.02. A ground plane with a size of $140 \mathrm{~mm} \times 80 \mathrm{~mm}$, which simulates a 5.7 -inch display, is printed on the bottom layer.

The detailed dimensions with the front and back views are shown in Figures 1(b) and Figure 1, respectively. The antenna element of the dual antenna, evolving from the design in [24] for heptaband applications, consists of a coupled-fed loop strip and a chip-inductor-loaded strip. The coupled-fed loop strip, comprising an L-shape feeding strip (section $\mathrm{AB}$ ) and a coupled loop strip (section CDG), mainly contributes to the higher frequency band. The chip-inductor-loaded strip, which mainly contributes to the lower frequency band, consists of a chip inductor (L1) and a folded metal strip (section EF). The folded metal strip is made up of a printed metal pattern on the bottom layer of the PCB and a folded copper plate (showing in yellow). The folded copper plate is a thin copper sheet which is supported by a foam. In Figure 1, the foam is omitted for better view.

To address the strong mutual coupling among the two elements, the neutralization line 1 (NL1, bottom layer of the PCB), neutralization line 2 (NL2, top layer of the PCB), and inverted-T branch (connecting to the ground at the bottom layer of the PCB) are introduced. NL1 and NL2 are embedded with chip inductors L2 and L3, respectively. Note that, there are two inductors L3 on the NL2. At last, to test the antenna, two 50- $\Omega$ microstrip feeding lines with the $1.5 \mathrm{~mm}$ width are printed on the top layer of the PCB.

\section{Working Mechanism of the Dual- Antenna System}

To study the proposed antenna, the decoupling method of the two neutralizations (NL) with the embedded inductor and the inverted-T branch is analyzed. Then, the working mechanism of the decoupling method is studied based on the current distributions. Finally, the effect of the embedded inductors is studied for better understanding. It should be noted that the inductors (L1, L2, and L3) in Figure 1 are set to be ideal inductor in simulations.

3.1. Function of the Two NLs and the Inverted-T Branch. To analyze the proposed antenna, the S-parameters of the dual-antenna system without the two NLs and inverted-T branch (Ant1), the dual-antenna system with only the two NLs (Ant2), and the dual-antenna system (the Proposed Ant) are illustrated in Figure 2. From Figure 2(b), one can find that S21 of Ant1 are higher and lower than $-10 \mathrm{~dB}$ at the desired lower (704-960 MHz) and higher (1710-2690 MHz) frequency bands, respectively. As the two NLs are applied, S21 of Ant2 at the desired lower frequency band $(704-960 \mathrm{MHz})$ is reduced significantly. However, S21 of Ant2 at the $1.71-1.93 \mathrm{GHz}$ band is increased to higher than $-10 \mathrm{~dB}$. When the inverted-T branch is applied, S21 of the Proposed Ant at the desired higher frequency band $(1710-2690 \mathrm{MHz})$ is reduced to less than $-10 \mathrm{~dB}$. Also, Figure 2(a) shows that the two NLs and the inverted-T branch have some small effects on S11. So, the two NLs and the inverted-T branch are mainly used to reduce the mutual couplings at the lower $(704-960 \mathrm{MHz})$ and higher (1710-2690 MHz) frequency bands, respectively.

To study the function of each NL, the S-parameters of the proposed antenna without NL2 (Ant3), the proposed antenna without NL1 (Ant4), and the proposed antenna (the Proposed Ant) are shown in Figure 3. Figure 3(a) illustrates that NL1 and NL2 have some effects on S11. Figure 3(b) shows that when NL1 or NL2 is applied alone, S21 of Ant3 and Ant 4 have a deep point at about $0.79 \mathrm{GHz}$ and $0.92 \mathrm{GHz}$, respectively. So, NL1 or NL2, when used alone, could decouple the dual-antenna system with a narrow bandwidth. When NL1 and NL2 are applied simultaneously, S21 of the Proposed Ant has two deep points at 0.73 and $0.88 \mathrm{GHz}$. Combining these two deep points, low mutual coupling within the wide band is achieved.

3.2. Current Distributions of Ant1, Ant2, and Proposed Ant. To analyze the working mechanism of the two NLs and the inverted-T branch, the scalar current distributions of Ant1, Ant2, and Proposed Ant at $0.73,0.88,1.8$, and $2.5 \mathrm{GHz}$ are illustrated in Figure 4. From Figure 4(a), it shows that the coupling current between the two antenna elements of Ant1 are strong and weak at the $0.73 / 0.88 \mathrm{GHz}$ and the 1.8 / $2.5 \mathrm{GHz}$, respectively. As shown in Figure 4(b), when the two 
TABLE 1: Figures of merit of octaband WWAN/LTE dual-antenna system.

\begin{tabular}{lccccc}
\hline References & Dimension $\left(\mathrm{mm}^{3}\right)$ & Decoupling method & Mutual coupling & Frequency band $^{\mathrm{a}}$ & ${\text { Efficiency }(\%)^{\mathrm{b}}}^{\text {(n) }}$ \\
\hline$[18]$ & - & Characteristic mode & $-10 \mathrm{~dB}$ & GSM900 & $>70$ \\
{$[19]$} & - & Characteristic mode & $-7.4 \mathrm{~dB}$ & GSM900 & $>40$ \\
{$[20]$} & - & One neutralization line & $-8 \mathrm{~dB}$ & LTE700/LTE2500 & $>15$ \\
{$[21]$} & $60 \times 10 \times 4$ & One neutralization line & $-10 \mathrm{~dB}$ & Heptaband & $>40$ \\
{$[22]$} & $80 \times 15 \times 5$ & Cross-neutralization line & $-10 \mathrm{~dB}$ & Octaband & $>30$ \\
{$[23]$} & $80 \times 15 \times 7$ & Grounded branch & $-10 \mathrm{~dB}$ & Octaband & $>32$ \\
Proposed & $80 \times 15 \times 6.8$ & Two neutralization lines & $-10 \mathrm{~dB}$ & Octaband & $>42$ \\
\hline
\end{tabular}

Heptaband: GSM850, GSM900, DCS, PCS, UMTS, LTE2300, and LTE2500. Octaband: heptaband with LTE700. Efficiency: the lowest efficiency within the frequency band.

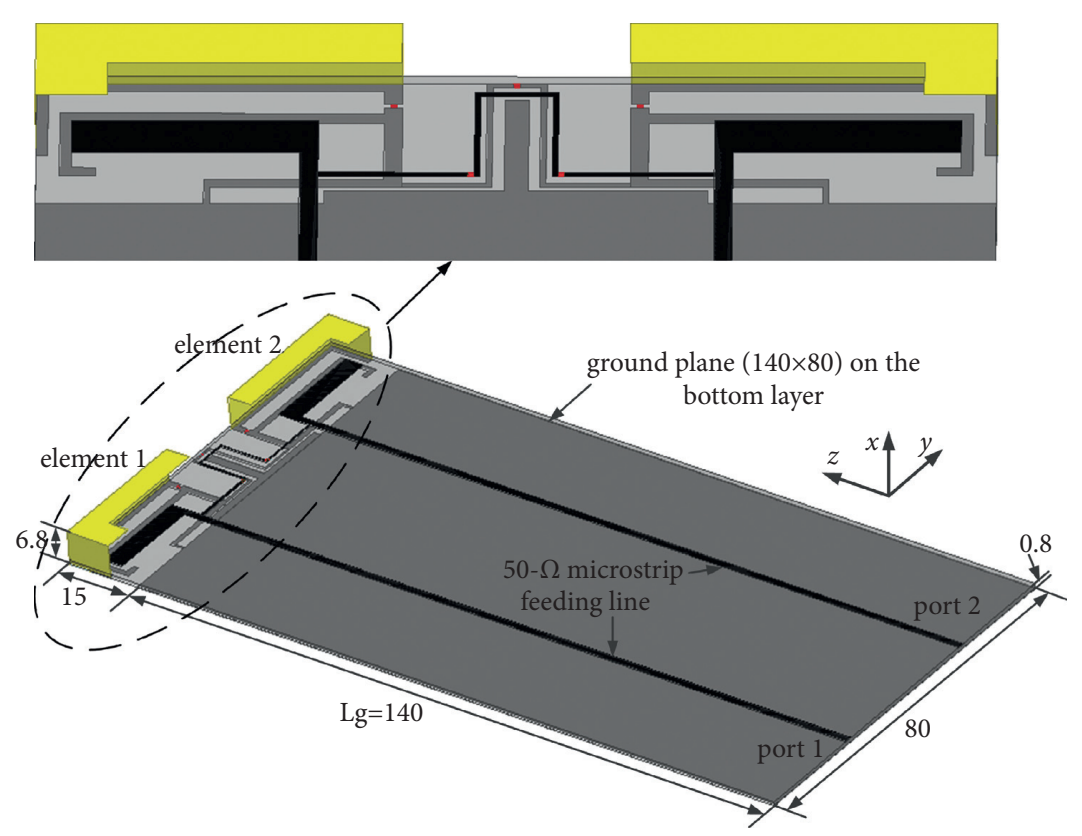

metal on the bottom layer of the PCB

metal on the top layer of the PCB

copper plate

(a)

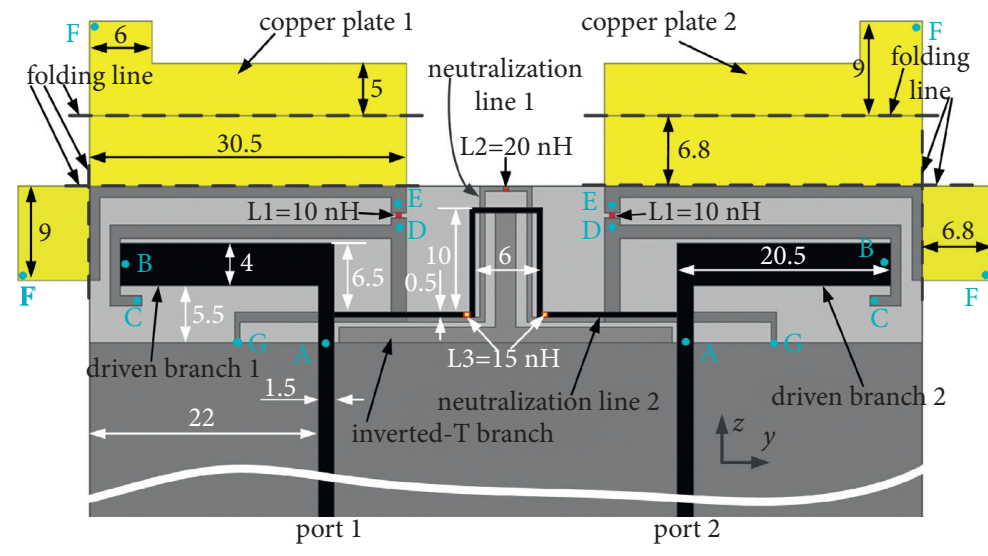

metal on the bottom layer of the $\mathrm{PCB}$

metal on the top layer of the PCB

copper plate

(b)

Figure 1: Continued. 


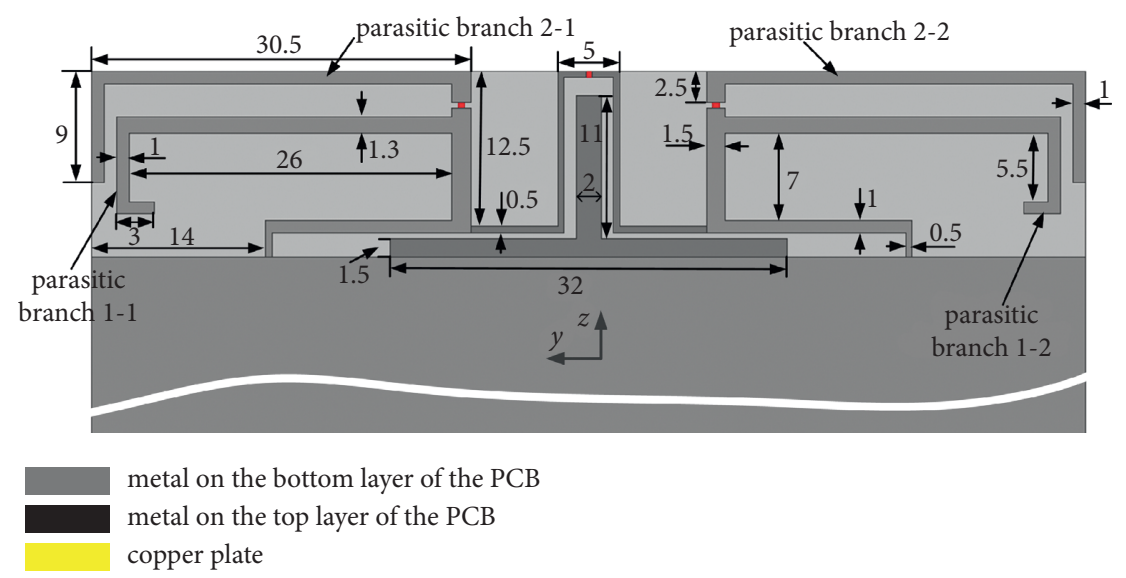

(c)

Figure 1: Antenna geometry with detailed dimensions. (a) Prospective view. (b) Front view. (c) Back view (the folded copper plate and the metal in the top layer are omitted).

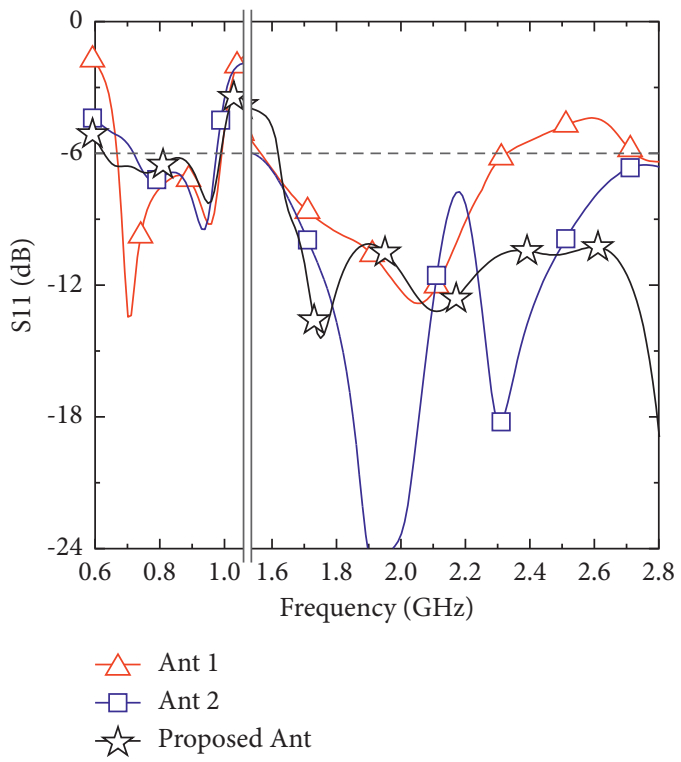

(a)

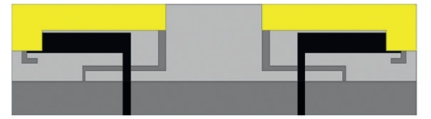

Ant1

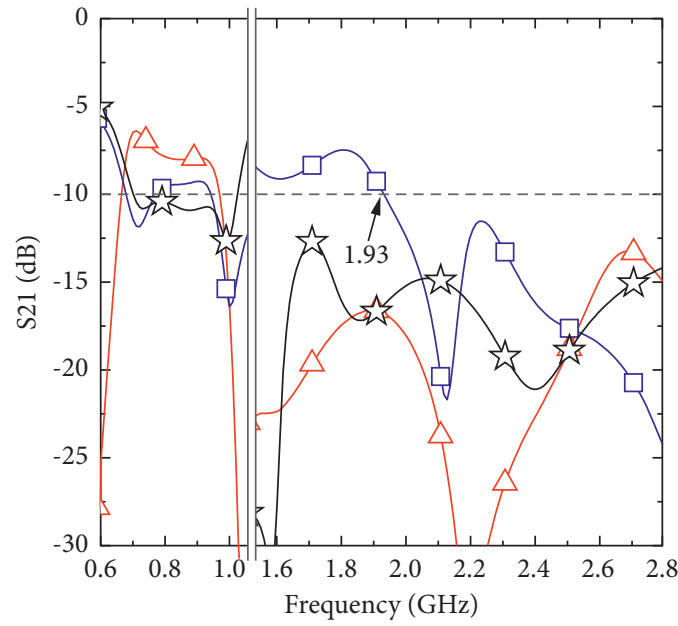

$\triangle$ Ant 1

$-\square-$ Ant 2

$-\frac{2}{2}$ Proposed Ant

(b)

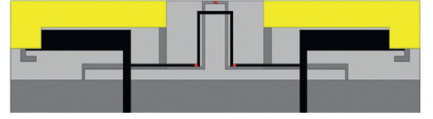

Ant2

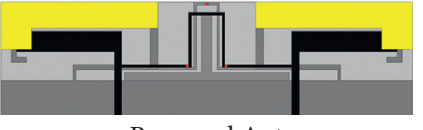

Proposed Ant

Figure 2: Simulated S-parameters of the Ant1 (without the two NLs and inverted-T branch), Ant2 (only with the two NLs), and the proposed Ant (with the two NLs and inverted-T branch). (a) S11. (b) S21.

NLs are applied, the two NLs add new coupling current between the two antenna elements to reduce the mutual coupling [17]. Thus, the coupling current between the two antenna elements of Ant2 at $0.73 / 0.88 \mathrm{GHz}$ are weakened. However, the coupling current of Ant2 at the $1.8 / 2.5 \mathrm{GHz}$ is strengthened. Figure 4(c) shows that, when the inverted-T branch is applied, the coupling current between the two antenna elements of Proposed Ant is weakened. In addition, Figures 4(b) and 4(c) show that NL1 and NL2 mainly introduce new current paths at $0.73 \mathrm{GHz}$ and $0.88 \mathrm{GHz}$, respectively.
3.3. Effect of the Embedded Inductors on the Mutual Coupling. In [17], the equivalent model of the neutralization line is established to analyze the working mechanism of the neutralization. Moving the neutralization line to the open end of antenna, increasing the width of the neutralization line, or increasing the length of the neutralization line can move the notch of the S21 to the lower frequency. The equivalent model in [17] can guide the design of neutralization line to be more intuitively. Here, to apply the neutralization line to decouple the dual-antenna system at the lower frequency band $(704-960 \mathrm{MHz})$, the inductors are embedded to the 


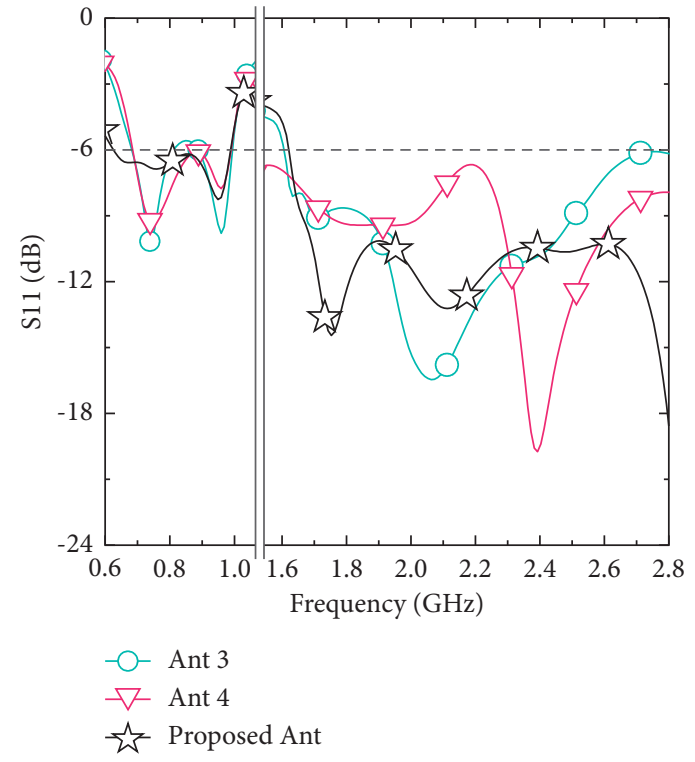

(a)

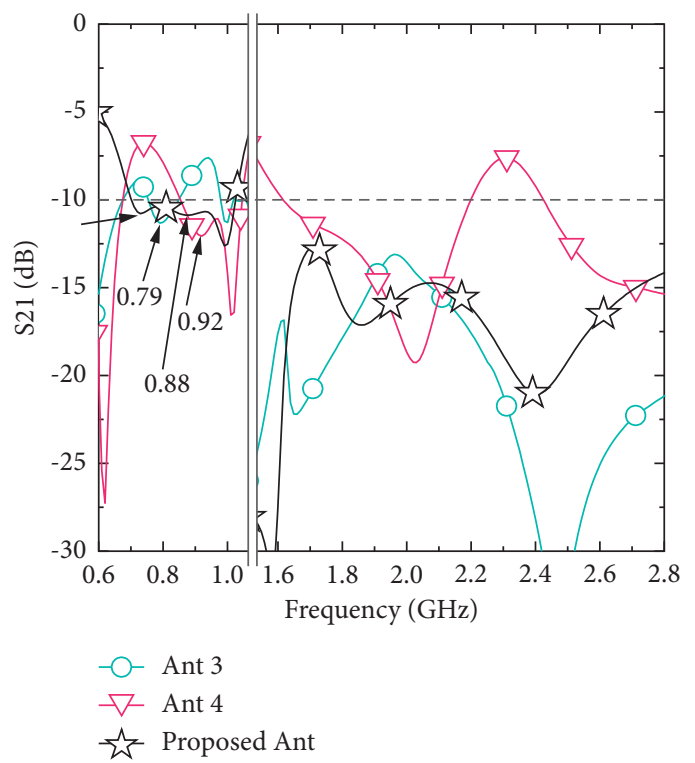

(b)

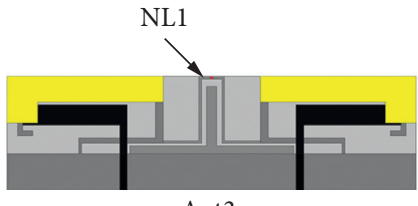

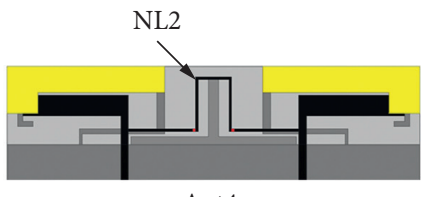

Ant4

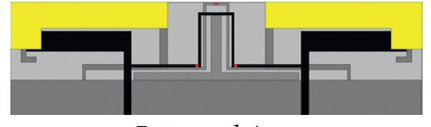

Proposed Ant

Figure 3: Simulated S-parameters of Ant3 (without NL2), Ant4 (without NL1), and Proposed Ant (with the two NLs). (a) S11. (b) S21.

(a)

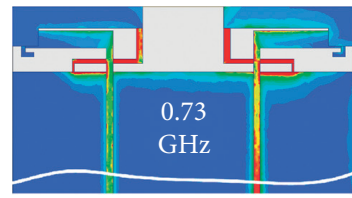

(b)

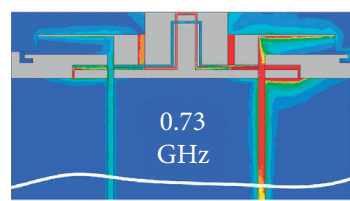

(c)

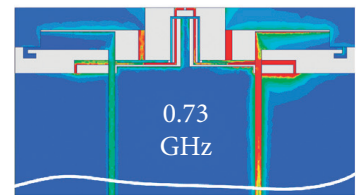

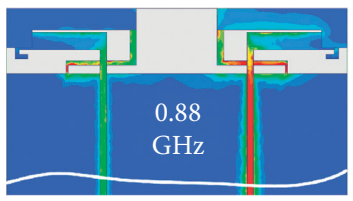
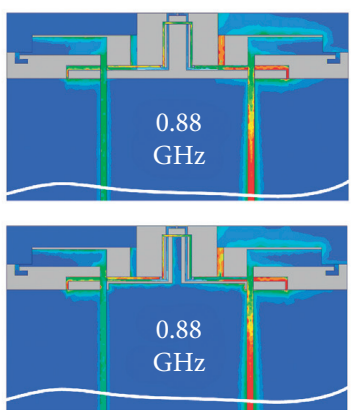
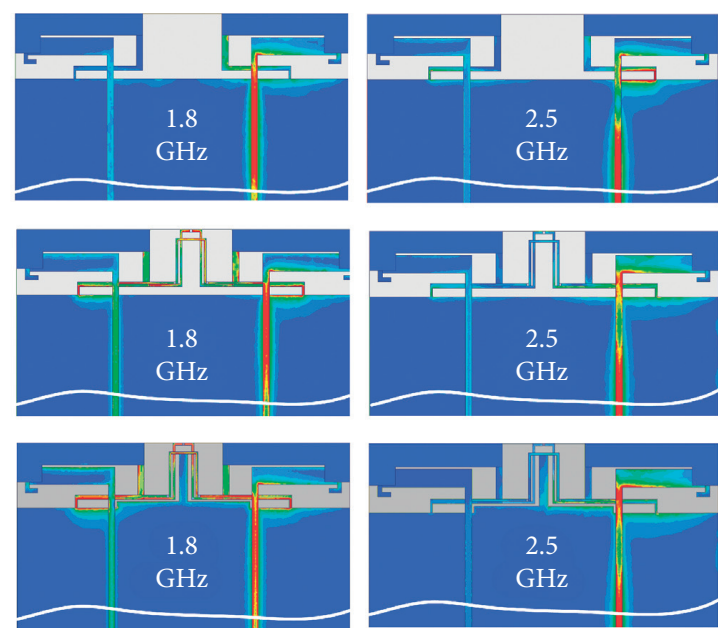

Figure 4: Scalar current distributions of Ant1, Ant2, and Proposed Ant at 0.73, 0.88, 1.8, and 2.5 GHz. (a) Ant1. (b) Ant2. (c) The Proposed Ant.

neutralization line. The inductors can lengthen the electrical length of the neutralization line which can move the notch of the S21 to the lower frequency band.

To better show the function of the embedded inductors, the effect of the embedded inductors on the decoupling performance is analyzed. Figures 5 and 6 show the S-parameters of the proposed antenna with different values of $\mathrm{L} 2$ and L3. From Figures 5(b) and 6(b), one can find that increasing the values of L2 and L3 would decrease the decoupling frequencies of NL1 and NL2, respectively. This phenomenon comes from the fact that increasing the values of L2 and L3 can lengthen the electrical length of the neutralization line. Thus, decoupling within the desired lower frequency band could be achieved by fine tuning the values of L2 and L3. Figures 5(a) and 6(a) show that the values of $\mathrm{L} 2$ and $\mathrm{L} 2$ have some effect the antenna impedance.

To study the antenna performance with practical environment, the effects of the chassis ground plane and the size of the ground plane on the antenna performance are analyzed. Figure 7 shows the installation positions of the chassis 


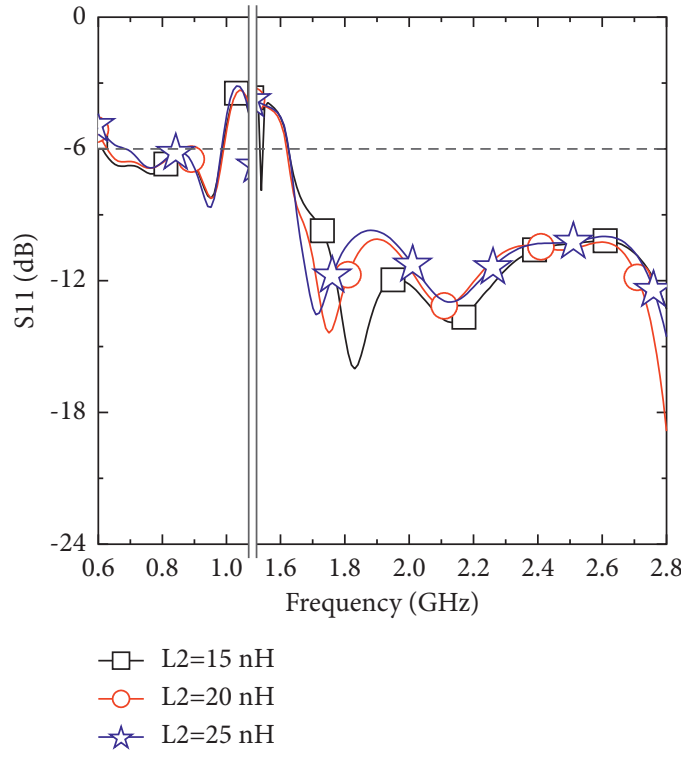

(a)

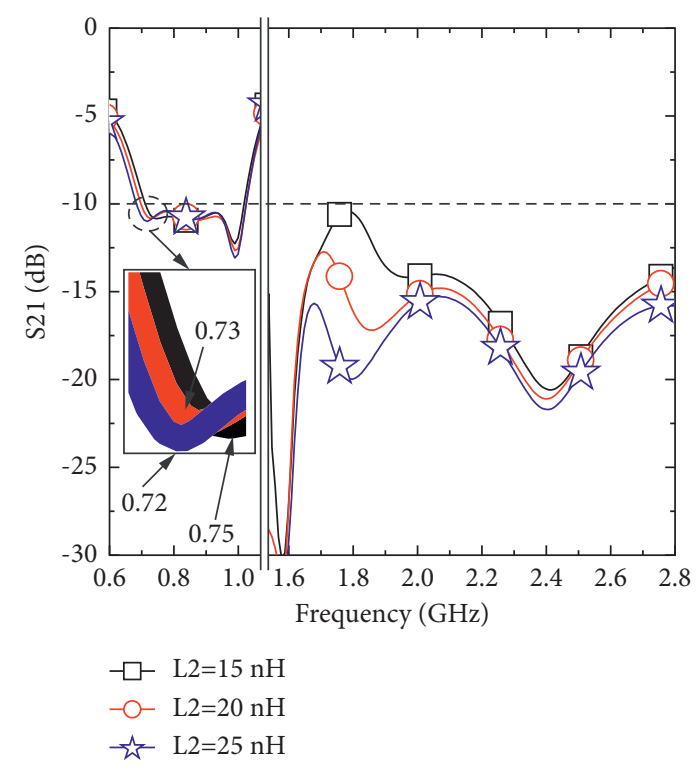

(b)

Figure 5: Simulated S-parameters of the proposed antenna with different values of L2. (a) S11. (b) S21.

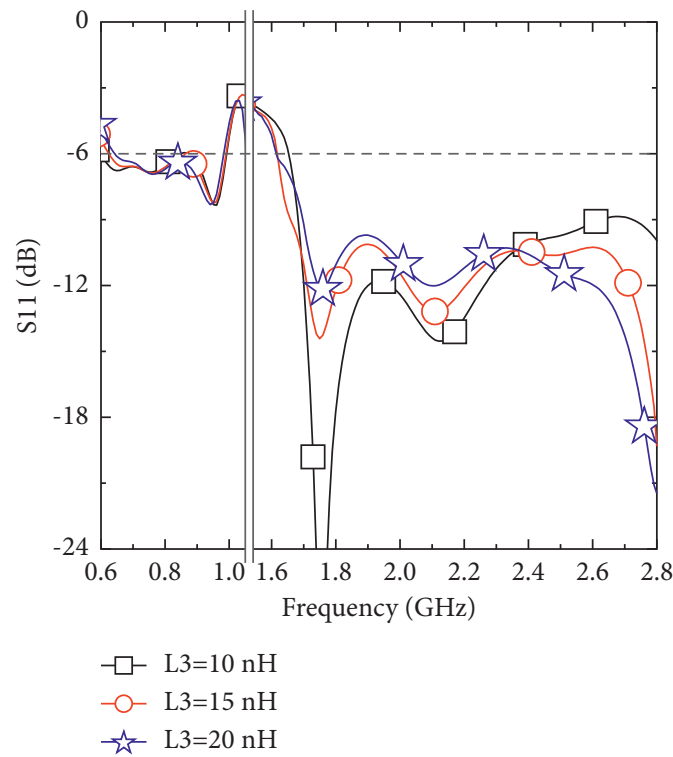

(a)

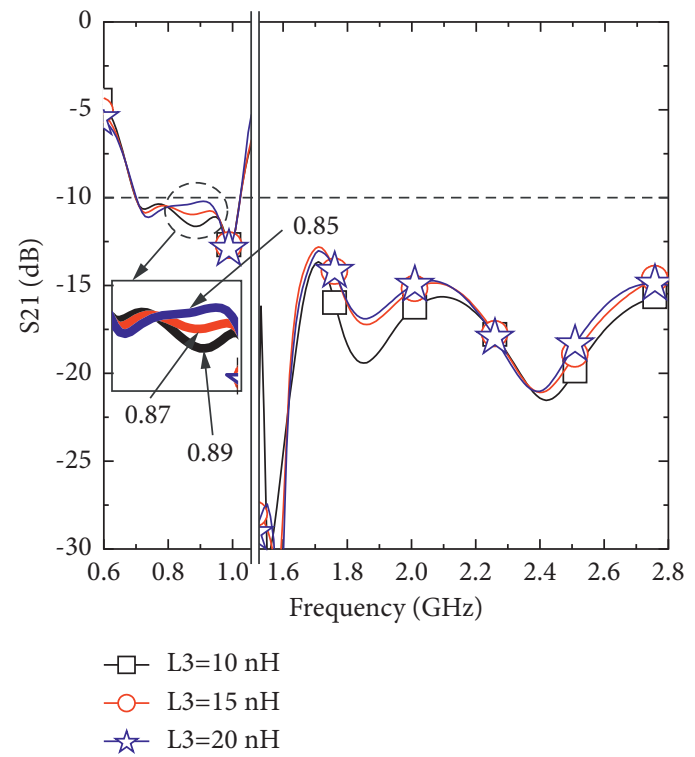

(b)

FIgURE 6: Simulated S-parameters of the proposed antenna with different values of L3. (a) S11. (b) S21.

ground plane. The size of the chassis ground plane is $130 \mathrm{~mm} \times 80 \mathrm{~mm} \times 2 \mathrm{~mm}$. The distance between the chassis ground plane and the ground plane is $2 \mathrm{~mm}$. Nine shorting pins are installed to connect the ground plane and the chassis ground. $d$ determines the distance between the antenna and the chassis ground. Figure 8 shows the effect of the parameter $d$ on the S-parameters. From Figure 8, one can find that if the chassis ground plane is installed on the mobile terminal, the S-parameters are affected a bit. As the distance between the antenna and the chassis ground plane increases, the effect decreases gradually. This phenomenon comes from that fact that, as the chassis ground plane is close to the antenna, it changes the coupling between the antenna and the ground plane. To further analyze the effect of the size of the ground plane on the antenna performance, Figure 9 shows the effect of the ground length on the S-parameters. Note that the results in Figure 9 are achieved without the chassis ground plane. From Figure 9, one can find that the length of the ground has some effects on the S-parameters at the lower frequency band while has a slight effect at the higher frequency band. The effect at the lower frequency band could be mitigated by fine tuning the antenna parameters. 


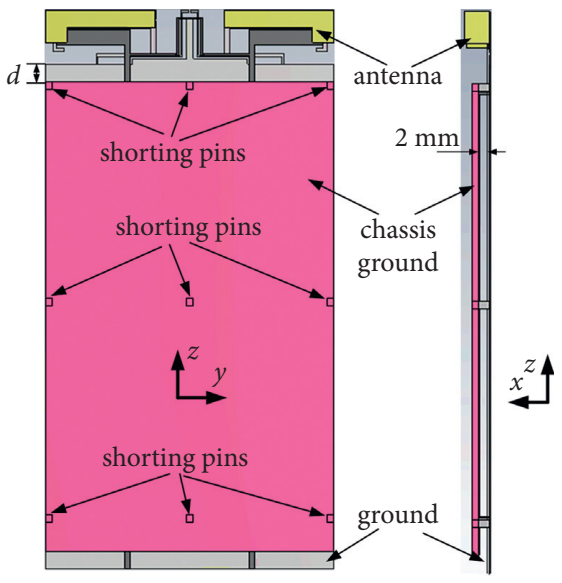

(a)

(b)

FIgURe 7: Installation position of the chassis ground plane. (a) Front view. (b) Side view.

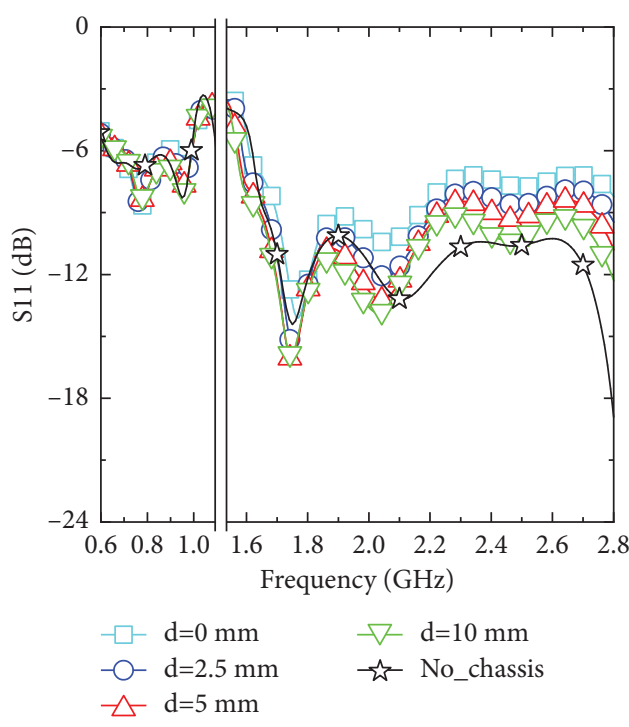

(a)

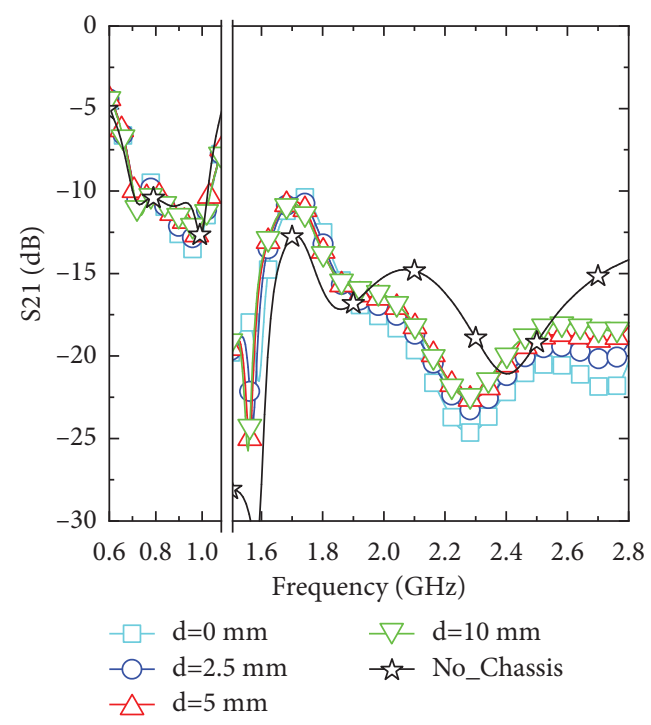

(b)

Figure 8: Effect of the chassis ground plane on the S-parameter. (a) S11. (b) S21.

\section{Experimental Results of the Proposed Antenna}

Based on the above analyses, an antenna prototype using the antenna geometry with dimensions in Figure 1 is manufactured. The keysight vector network analyzer E5071B is used to test the S-parameters. The ETS-Lindgren AMS8500 anechoic chamber is used to test the radiation performance.

4.1. S-Parameters. The measured and simulated S-parameters of the proposed decoupled dual-antenna system are given in Figure 10. The measured impedance bandwidths with $\mathrm{S} 11<-6 \mathrm{~dB}$ reach $0.3 \mathrm{GHz}(0.69-0.99 \mathrm{GHz})$ and $1.2 \mathrm{GHz}$ $(1.66-2.86 \mathrm{GHz})$. Between 0.69-0.99 GHz and 1.66-2.76 GHz bands, the measured S21 are lower than $-10 \mathrm{~dB}$. The corresponding simulated impedance bandwidths are $0.36 \mathrm{GHz}$ $(0.63-0.99 \mathrm{GHz})$ and $1.48 \mathrm{GHz}(1.61-3.09 \mathrm{GHz})$. Between
0.7-0.99 GHz and 1.61-3.09 GHz, the simulated S21 are lower than $-10 \mathrm{~dB}$. Both the simulated and measured bandwidths with $\mathrm{S} 11<-6 \mathrm{~dB}$ and $\mathrm{S} 21<-10 \mathrm{~dB}$ could cover the desired working bands of LTE700, GSM850, GSM900, DCS, PCS, UMTS, LTE2300, and LTE2500. The differences between the simulated and measured S-parameters might come from the simulated and measured errors.

4.2. Radiation Performance. The measured three-dimensional (3D) radiation patterns of the proposed antenna at the $0.75,0.85,0.95,1.8,2.2$, and $2.6 \mathrm{GHz}$ are shown in Figures 11 and 12 which illustrate the simulated and measured total antenna gains and efficiencies. From Figure 11, one can find that the two antenna elements of the proposed dual-antenna system could radiate power to complementary space. Figure 12 shows that the measured total antenna efficiencies are about $42.6 \%-60 \%$ and $58.3 \%-78.7 \%$ at the lower 


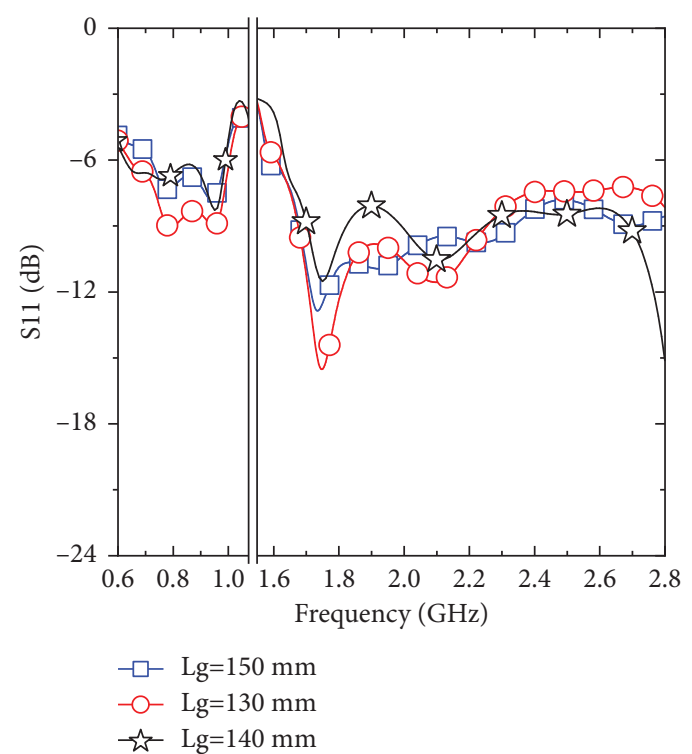

(a)

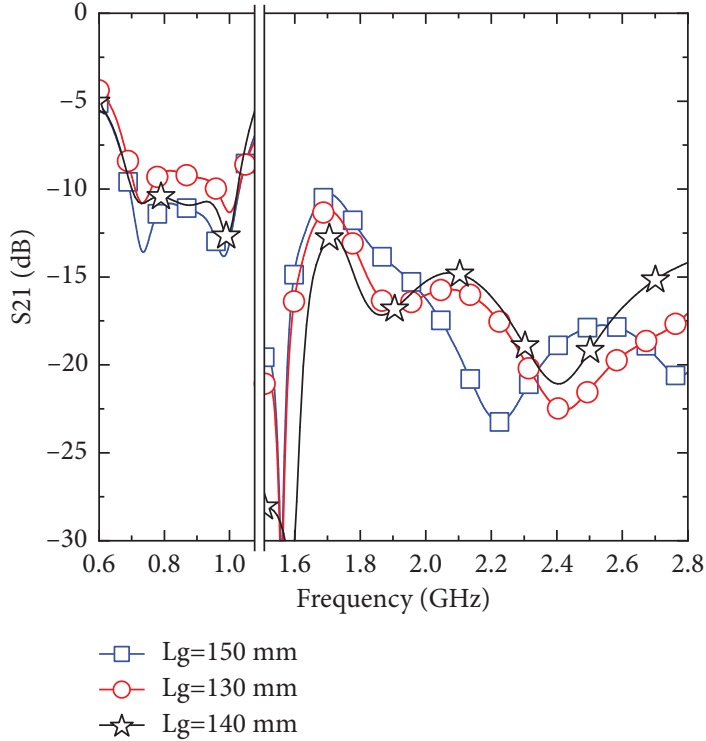

(b)

Figure 9: Effect of the ground length on the S-parameters. (a) S11. (b) S21.

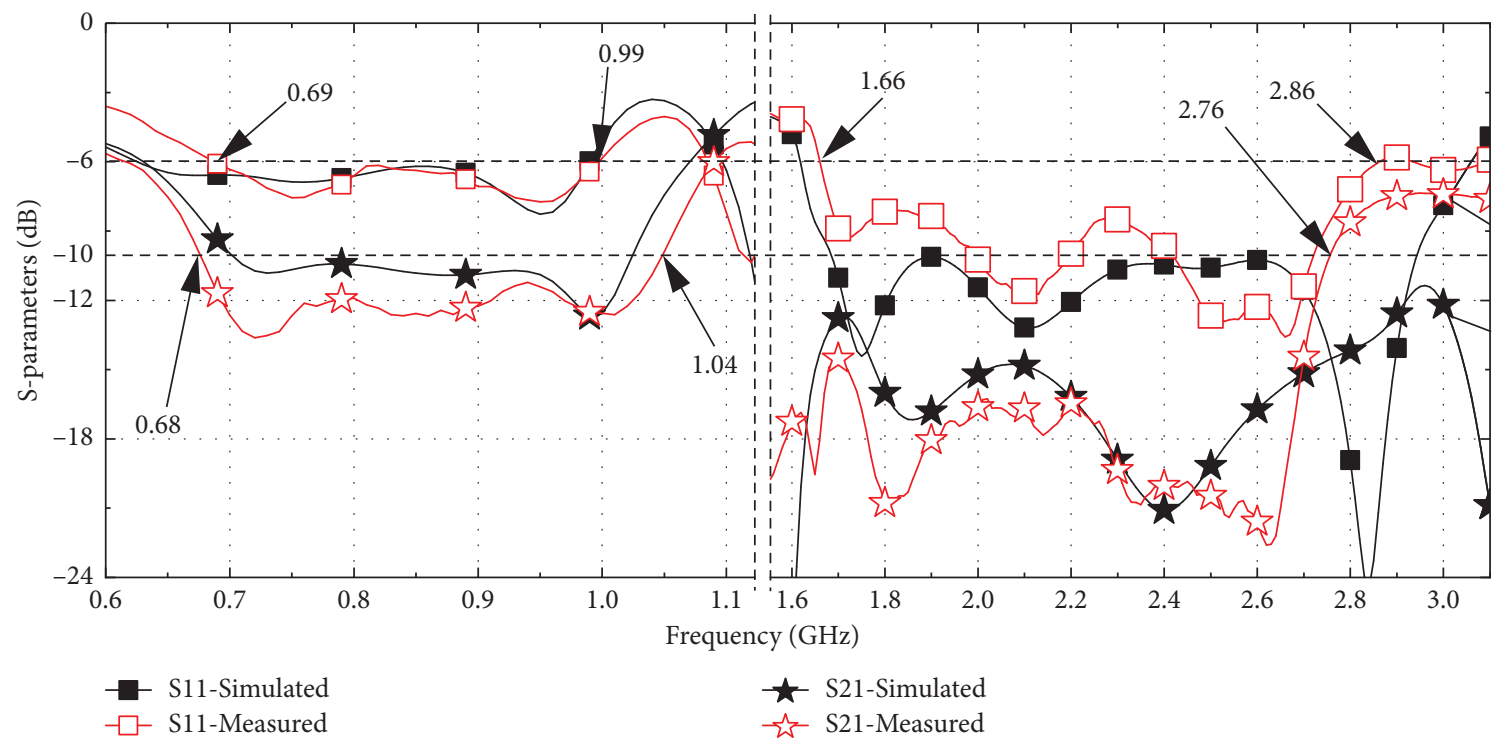

FIgURE 10: Simulated and measured S-parameters of the proposed antenna.

(704-960 MHz) and higher $(1710-2690 \mathrm{MHz})$ frequency bands, respectively. The simulated ones are about 50\%-56\% and $50.4 \%-71.2 \%$. The measured antenna gains are about $-0.69-0.31 \mathrm{dBi}$ and $1.2-5.6 \mathrm{dBi}$ at the lower $(704-960 \mathrm{MHz})$ and higher (1710-2690 MHz) frequency bands, respectively. The simulated ones are about $-0.22-0.58 \mathrm{dBi}$ and 1.7-4.4 dBi. The differences between the simulated and measured results might come from the simulated error, the measured error, and the manufacture error.

4.3. Diversity Performance. The envelop correlation coefficient $\left(\rho_{e}\right)$ and mean effective gain (MEG) are two important criterions to evaluate the performance of a multiantenna system. $\rho_{e}$ is the correlation of the signals received by two different elements. Supposing the reflection and diffraction are rich, the channel response is Rayleigh-distributed, and the multipath signal is 3D uniform distributed in a full sphere, the complex correlation coefficient $\left(\rho_{c}\right)$, and the envelop correlation coefficient $\left(\rho_{e}\right)$ can be evaluated as [25]

$$
\rho_{e} \approx\left|\rho_{c}\right|^{2}=\mid \frac{\iint A_{12}(\Omega) \mathrm{d} \Omega}{\sqrt{\iint A_{11}(\Omega) \mathrm{d} \Omega \sqrt{\left.\iint A_{22}(\Omega) \mathrm{d} \Omega\right|^{2}}}} .
$$



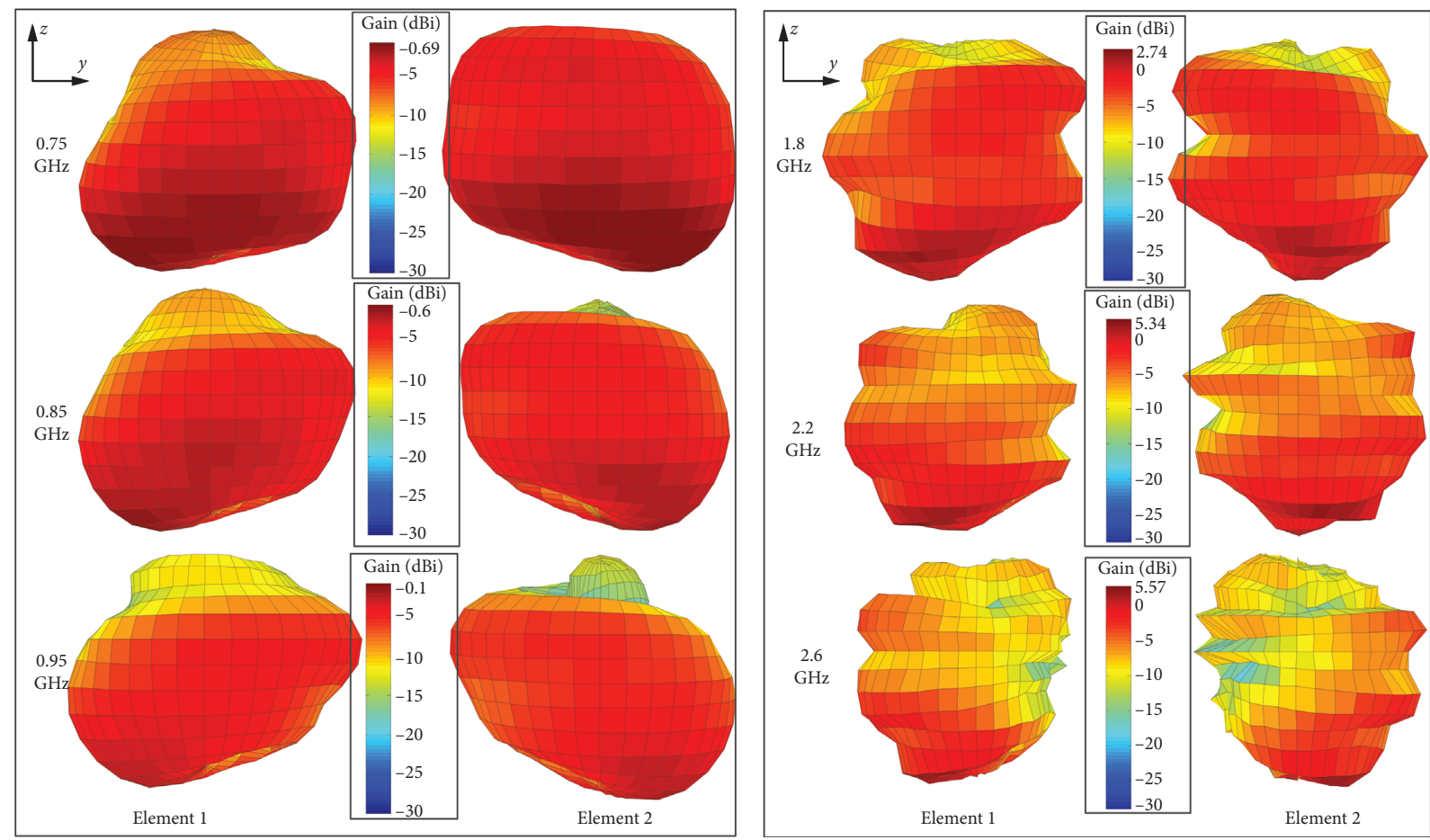

FIgURE 11: Measured 3D radiation patterns of the proposed antenna.

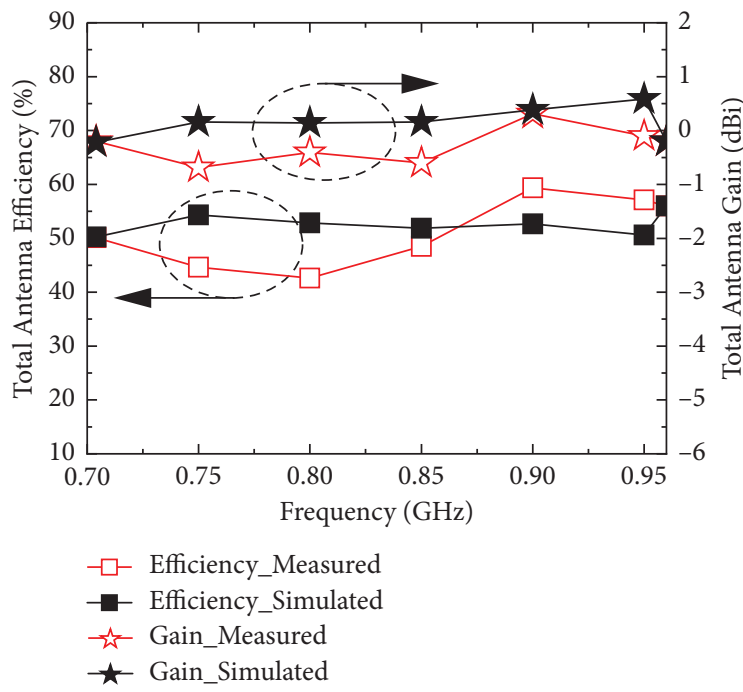

(a)

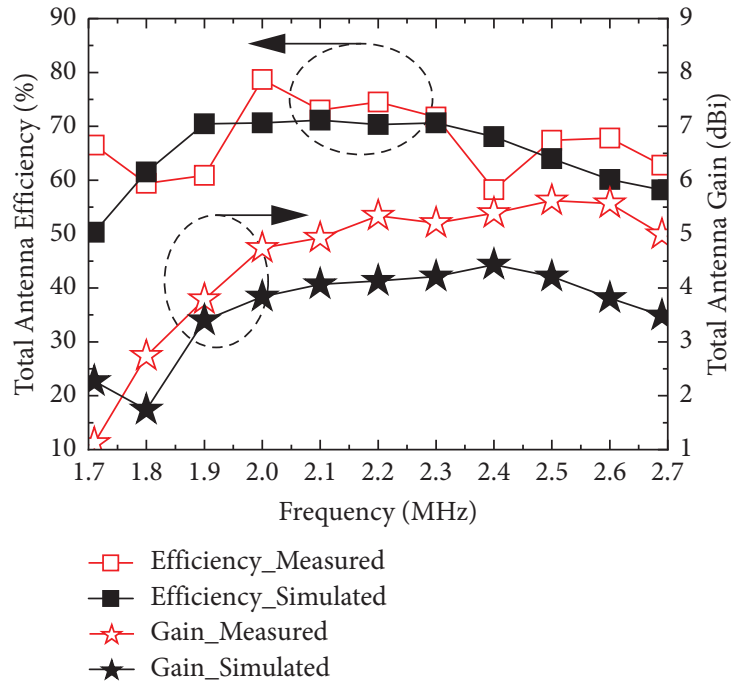

(b)

FiguRE 12: Simulated and measured total antenna gains and efficiencies of the proposed antenna. (a) At the lower frequency band. (b) At the higher frequency band.

$$
A_{i j}=\Gamma \cdot E_{\theta, i}(\Omega) \cdot E_{\theta, j}^{*} \cdot p_{\theta}(\Omega)+E_{\phi, i} \cdot E_{\phi, j}^{*} \cdot p_{\phi}(\Omega),
$$

where $E_{\theta}$ and $E_{\phi}$ are the $\theta$ - and $\phi$-components of the complex electrical field, respectively, $p_{\theta}$ and $p_{\phi}$ are the $\theta$ - and $\phi$-components of the probability distribution function of the incoming wave, respectively, and $\Gamma$ is the cross-polarization discrimination (XPD) (ratio of vertical to horizontal power density) of the incident filed. In this paper, $\Gamma$ of $0 \mathrm{~dB}$ and $6 \mathrm{~dB}$, which are the average values in an indoor and an urban fading environment [25], respectively, and are assumed.
MEG, representing the mean power received from each element, is the ratio of the mean received power of each element to the mean incident power. It can be obtained from the radiation patterns and the statistics of the channel as $[26,27]$

$$
\mathrm{MEG}_{i}=\iint\left[\frac{\Gamma}{1+\Gamma} \cdot G_{\theta, i}(\Omega) \cdot p_{\theta}(\Omega)+\frac{1}{1+\Gamma} \cdot G_{\phi, i}(\Omega) \cdot p_{\phi}(\Omega)\right] \mathrm{d} \Omega,
$$




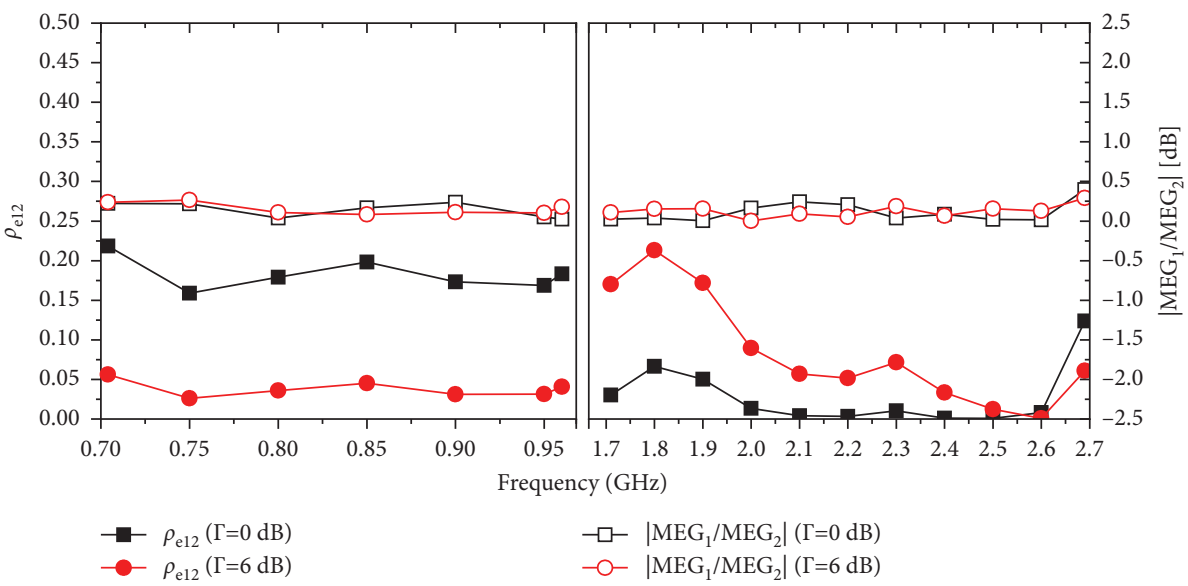

FIGURE 13: Measured envelop correlation coefficients and mean effective gain of the proposed dual-antenna system.
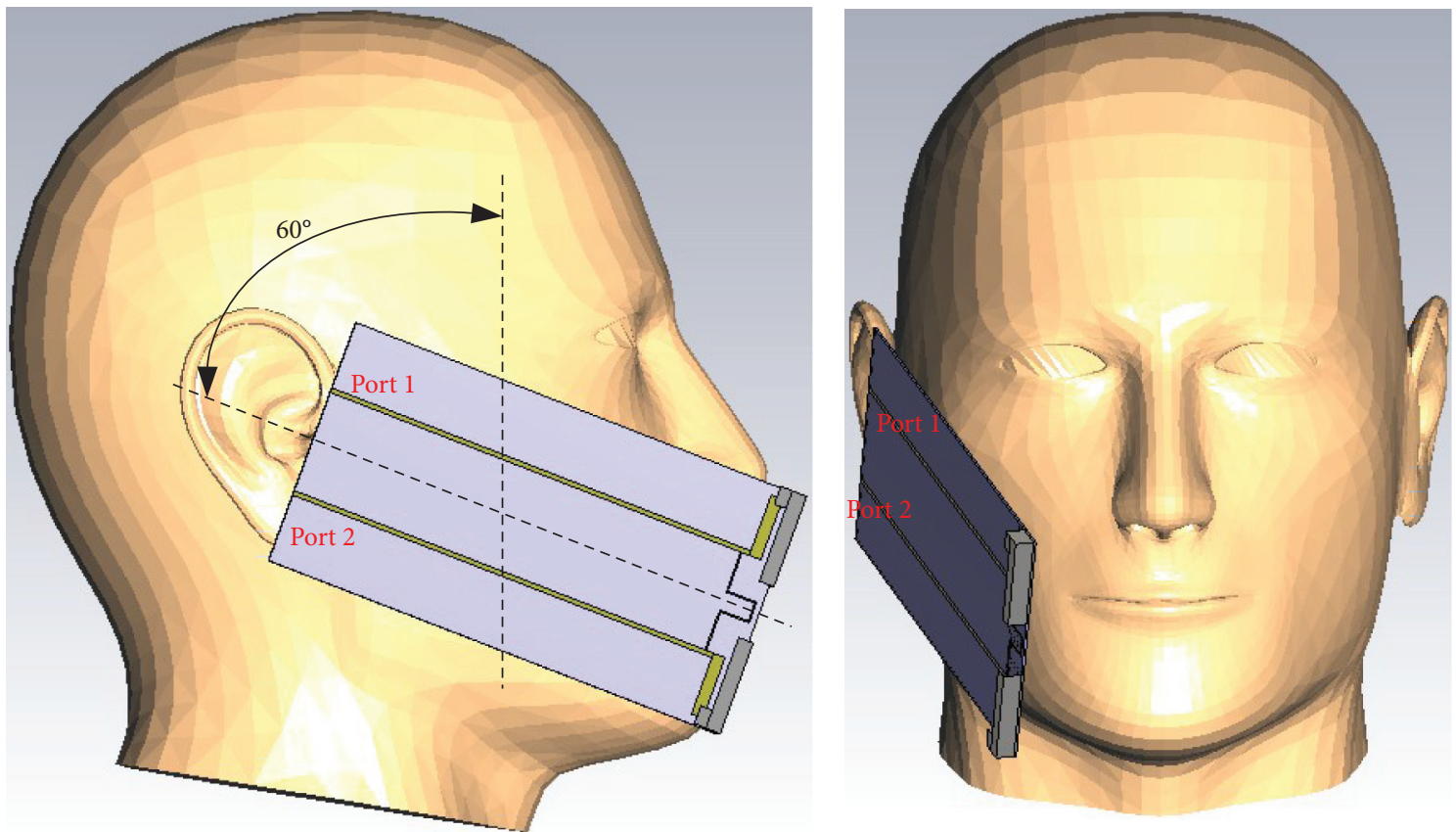

FIgURE 14: SAR simulation model of the proposed antenna.

where $G_{\theta}$ and $G_{\phi}$ are the $\theta$ - and $\phi$-polarized components of the antenna power gain pattern.

According to (1) and (3), $\rho_{e}$ and MEG are calculated using the measured $3 \mathrm{D}$ radiation patterns. The evaluated $\rho_{e}$ and MEG are shown in Figure 13. As can be seen from Figure 13 , in the indoor $(\Gamma=0 \mathrm{~dB})$ or the urban $(\Gamma=6 \mathrm{~dB})$ fading environment, the envelop correlation coefficient at the lower frequency band and the higher frequency band is lower than 0.22 and 0.21 , respectively. The ratio of the mean effective gain at the lower frequency band and the higher frequency band is lower than $0.26 \mathrm{~dB}$ and $0.4 \mathrm{~dB}$, respectively. In summary, the diversity performance of the proposed dual-antenna system satisfies the criterions of low correlation ( $\rho_{e}$ is lower than 0.5 ) and comparable average received power $\left(\left|M E G_{1}-M_{E} G_{2}\right|\right.$ is lower than $3 \mathrm{~dB})$ [27].
4.4. SAR Performance. To study the specific absorption rate (SAR) of the proposed dual-antenna system to investigate the safety concerns of the user, Figure 14 shows the SAR simulation model of the proposed dual-antenna system. In the simulation model, the dual-antenna system is placed near the head phantom ear with a distance of $1 \mathrm{~mm}$ and is inclined to the vertical line by 60 degrees. To reduce the SAR, the dual-antenna system is located at the bottom part of the mobile phone. For SAR testing, the input power is $24 \mathrm{dBm}(0.25 \mathrm{~W})$ for $740 \mathrm{MHz}, 860 \mathrm{MHz}$, and $925 \mathrm{MHz}$ and $21 \mathrm{dBm}(0.125 \mathrm{~W})$ for $1795 \mathrm{MHz}$, $1920 \mathrm{MHz}, 2045 \mathrm{MHz}, 2350 \mathrm{MHz}$, and $2595 \mathrm{MHz}$. The simulated 10-g SAR values are listed in Table 2. Note that, in Table 2, the SAR values are achieved under the condition that one port is excited while the other one is terminated to a $50-\Omega$ matching load. Table 2 shows the 
TABLE 2: Simulated SAR values for $10 \mathrm{~g}$ head tissue.

\begin{tabular}{lccccccc}
\hline Frequency $(\mathrm{MHz})$ & 860 & 925 & 1795 & 1920 & 2045 & 2350 & 2595 \\
\hline $\begin{array}{l}\text { Input power }(\mathrm{dBm}) \\
\text { 10-G SAR }(\mathrm{W} / \mathrm{Kg}):\end{array}$ & 24 & 24 & 21 & 21 & 21 & 21 & 21 \\
$\begin{array}{l}\text { Port 1 } \\
\text { 10-G SAR (W/Kg): }\end{array}$ & 0.45 & 0.43 & 0.35 & 0.13 & 0.32 & 0.52 & 0.46 \\
Port 2 & 0.58 & 0.57 & 0.35 & 0.25 & 0.41 & 0.64 & 0.57 \\
\hline
\end{tabular}

SAR values for the proposed dual-antenna system are below the SAR limit of $2.0 \mathrm{~W} / \mathrm{kg}$ for $10 \mathrm{~g}$ tissue which is acceptable for practical applications [28].

\section{Conclusions}

This study presents an octaband WWAN/LTE dual-antenna system for smart phones. The proposed antenna system consists of two antenna elements with symmetrical geometry, two NLs with an embedded inductor and an inverted-T branch. The S-parameters with different geometries and scalar current distribution of the proposed antenna is applied to analyze the working mechanism. A fabricated prototype has the measured $-6 \mathrm{~dB}$ impedance bandwidths covering all the desired frequency bands of LTE700, GSM850, GSM900, DCS, PCS, UMTS, LTE2300, and LTE2500 bands. Also, within these frequency bands, the measured mutual couplings are lower than $-10 \mathrm{~dB}$. Measured 3D radiation patterns cover symmetrical space. The measured efficiency is higher than $42 \%$ which is acceptable for practical applications. The diversity performance of the proposed dual-antenna system satisfies the criterions of low correlation and comparable average received power. The SAR performance is acceptable for practical applications. The moderate antenna size with high efficiency could be applied for the low-end mobile terminals.

\section{Data Availability}

No data were used to support this study.

\section{Conflicts of Interest}

The authors declare that they have no conflicts of interest.

\section{References}

[1] J. G. Andrews, S. Buzzi, W. Choi et al., "What will 5G Be?" IEEE Journal on Selected Areas in Communications, vol. 32, no. 6, pp. 1065-1082, Jun. 2014.

[2] Z. Zhang, Antenna Design for Mobile Devices, Wiley, Hoboken, NJ, USA, 2nd edition, 2017.

[3] W. Hong, "Solving the 5G mobile antenna puzzle: assessing future directions for the $5 \mathrm{G}$ mobile antenna paradigm shift," IEEE Microwave Magazine, vol. 18, no. 7, pp. 86-102, 2017.

[4] L. Chang, Y. Yu, K. Wei, and H. Wang, "Polarization-orthogonal Co-frequency dual antenna pair suitable for 5G MIMO smartphone with metallic bezels," IEEE Transactions on Antennas and Propagation, vol. 67, no. 8, pp. 5212-5220, 2019.

[5] C. Deng, X. Lv, and Z. Feng, "Wideband dual-mode patch antenna with compact CPW feeding network for pattern diversity application," IEEE Transactions on Antennas and Propagation, vol. 66, no. 5, pp. 2628-2633, 2018.

[6] L. Sun, Y. Li, Z. Zhang, and M. F. Iskander, "A compact planar omnidirectional MIMO array antenna with pattern phase diversity using folded dipole element," IEEE Transactions on Antennas and Propagation, vol. 67, no. 3, pp. 1688-1696, 2019.

[7] A. Ren, Y. Liu, and C.-Y.-D. Sim, "A compact building block with two shared-aperture antennas for eight-antenna MIMO array in metal-rimmed smartphone," IEEE Transactions on Antennas and Propagation, vol. 67, no. 10, pp. 6430-6438, 2019.

[8] K. L. Wong, B. W. Lin, and S. E. Lin, "High-isolation conjoined loop multi-input multi-output antennas for the fifthgeneration tablet device," Microwave and Optical Technology Letters, vol. 61, no. 1, pp. 111-119, 2019.

[9] K.-L. Wu, C. Wei, X. Mei, and Z.-Y. Zhang, “Array-antenna decoupling surface," IEEE Transactions on Antennas and Propagation, vol. 65, no. 12, pp. 6728-6738, 2017.

[10] A. Zhao, Z. Ren, and S. Wu, "broadband MIMO antenna system for $5 \mathrm{G}$ operations in mobile phones," International Journal of RF and Microwave Computer-Aided Engineering, vol. 29, Article ID e21857, 2019.

[11] D. Huang, Z. Du, and Y. Wang, "Slot antenna array for fifth generation metal frame mobile phone applications," International Journal of RF and Microwave Computer-Aided Engineering, vol. 29, Article ID e21841, 2019.

[12] L. Sun, Y. Li, Z. Zhang, and H. Wang, "Self-decoupled MIMO antenna pair with shared radiator for $5 \mathrm{G}$ smartphones," IEEE Transactions on Antennas and Propagation, vol. 68, no. 5, pp. 3423-3432, 2020.

[13] H. Xu, S. S. Gao, H. Zhou, H. Wang, and Y. Cheng, "A highly integrated MIMO antenna unit: differential/common mode design," IEEE Transactions on Antennas and Propagation, vol. 67, no. 11, pp. 6724-6734, 2019.

[14] J. Kornprobst, T. J. Mittermaier, R. A. M. Mauermayer et al., "Compact uniform circular quarter-wavelength monopole antenna arrays with wideband decoupling and matching networks," IEEE Transactions on Antennas and Propagation, vol. 69, no. 2, pp. 769-783, 2021.

[15] D. Huang, Z. Du, and Y. Wang, "Dual antenna system for metal frame mobile phone applications," International Journal of RF and Microwave Computer-Aided Engineering, vol. 30, Article ID e22110, 2020.

[16] L. Zhao and K.-L. Wu, "A decoupling technique for fourelement symmetric arrays with reactively loaded dummy elements," IEEE Transactions on Antennas and Propagation, vol. 62, no. 8, pp. 4416-4421, 2014.

[17] Y. Wang and Z. Du, "A wideband printed dual-antenna with three neutralization lines for mobile terminals," IEEE Transactions on Antennas and Propagation, vol. 62, no. 3, pp. 1495-1500, 2014.

[18] H. Li, Z. T. Miers, and B. K. Lau, "Design of orthogonal MIMO handset antennas based on characteristic mode manipulation at frequency bands below $1 \mathrm{GHz}$," IEEE Transactions on Antennas and Propagation, vol. 62, no. 5, pp. 2756-2766, 2014.

[19] C. Deng, Z. Feng, and S. V. Hum, "MIMO mobile handset antenna merging characteristic modes for increased bandwidth," IEEE Transactions on Antennas and Propagation, vol. 64, no. 7, pp. 2660-2667, 2016.

[20] I. Dioum, A. Diallo, S. M. Farssi, and C. Luxey, "A novel compact dual-band LTE antenna-system for MIMO operation," IEEE Transactions on Antennas and Propagation, vol. 62, no. 4, pp. 2291-2296, 2014. 
[21] Y.-L. Yong-Ling Ban, Z.-X. Zhong-Xiang Chen, Z. Zhi Chen, K. Kai Kang, and J. L.-W. Li, "Decoupled hepta-band antenna array for WWAN/LTE smartphone applications," IEEE Antennas and Wireless Propagation Letters, vol. 13, pp. 999-1002, 2014.

[22] S. Shang Wang and Z. Zhengwei Du, "Decoupled dual-antenna system using crossed neutralization lines for LTE/ WWAN smartphone applications," IEEE Antennas and Wireless Propagation Letters, vol. 14, pp. 523-526, 2015.

[23] S. Wang and Z. Du, "A multiband dual-antenna system with a folded fork-shaped ground branch and folded asymmetric U-shaped slots for smartphone applications," IEEE Antennas and Wireless Propagation Letters, vol. 14, pp. 1626-1629, 2015.

[24] K.-L. Wong, M.-F. Tu, C.-Y. Wu, and W.-Y. Li, "On-board 7band WWAN/LTE antenna with small size and compact integration with nearby ground plane in the mobile phone," Microwave and Optical Technology Letters, vol. 52, no. 12, pp. 2847-2853, 2010.

[25] S. C. K. Ko and R. D. Murch, "Compact integrated diversity antenna for wireless communications," IEEE Transactions on Antennas and Propagation, vol. 49, no. 6, pp. 954-960, 2001.

[26] R. G. Vaughan and J. B. Andersen, "Antenna diversity in mobile communications," IEEE Transactions on Vehicular Technology, vol. 36, no. 4, pp. 149-172, 1987.

[27] T. Taga, "Analysis for mean effective gain of mobile antennas in land mobile radio environments," IEEE Transactions on Vehicular Technology, vol. 39, no. 2, pp. 117-131, 1990.

[28] Y.-L. Ban, Y.-F. Qiang, Z. Chen, K. Kang, and J.-H. Guo, “A dual-loop antenna design for hepta-band WWAN/LTE metalrimmed smartphone applications," IEEE Transactions on Antennas and Propagation, vol. 63, no. 1, pp. 48-58, 2015. 